\title{
KAJIAN LITERATUR : ARAHAN PENGEMBANGAN WILAYAH BERBASIS STRUKTUR GEOLOGI KAWASAN DI PULAU BELITUNG
}

\author{
Nabil Fahrezy ${ }^{a}$, Feldian Hendargi ${ }^{\text {a }}$, Hasti Widyasamratri ${ }^{a}$ \\ a Universitas Islam Sultan Agung, Indonesia \\ E-mail korespondensi: nabilfahrezy7@gmail.com,dargifldian@gmail.com,widya_samratri@unissula.ac.id
}

\begin{abstract}
Abstrak: Keberagaman di Indonesia merupakan pengaruh negara yang berbentuk kepulauan sehingga karakteristik geologi pada setiap wilayah akan berbeda, karena itu pengembangan di setiap wilayah akan berbeda. Pengembangan wilayah berbasis struktur geologi kawasan merupakan kajian dari pengembangan suatu wilayah dengan mengkaji struktur geologi yang terdapat pada kawasan tertentu. Perbedaan struktur geologi ini harus diperhatikan agar tidak terjadi ketidakcocokan, khususnya untuk pengembangan wilayah Pulau Belitung yang mulai tumbuh seiring dengan beralihnya kegiatan pertambangan ke kegiatan pariwisata sebagai prioritas pengembangan wilayah, khususnya di Kabupaten Belitung dan Kabupaten Belitung Timur.
\end{abstract}

Kata kunci: Struktur Geologi, Pengembangan Wilayah, Formasi Batuan.

Abstract: Diversity in Indonesia is the influence of a country in the form of an archipelago so that the geological characteristics of each region will be different, therefore the development in each region will be different. Regional development based on regional geological structure is a study of the development of an area by studying the geological structure found in a particular area. This difference in geological structure must be considered so that there is no mismatch, especially for the development of the Belitung Island area which began to grow along with the shift from mining activities to tourism activities as a priority for regional development, especially in Belitung Regency and East Belitung Regency.

Keywords:. Keywords: Geological Structure, Regional Development, Rocks Formation.

Fahrezy, Nabil; Hendargi, Feldian; Widyasamratri, Hasti. (2021). Kajian Literatur : Arahan Pengembangan Wilayah Berbasis Struktur Geologi Kawasan Di Pulau Belitung, 2(2), 29-36. doi: 10.26418/uniplan.v2i2.50028

\section{PENDAHULUAN}

Keberagaman di Indonesia merupakan pengaruh negara yang berbentuk kepulauan sehingga karakteristik geologi pada setiap wilayah akan berbeda. Sebagai contoh, wilayah Republik Indonesia memiliki berbagai macam struktur geologi yang terbagi menjadi tiga kategori, yaitu bagian utara yang dipengaruhi dari lempeng Eurasia, bagian barat dan selatan yang dipengaruhi dari lempeng Indo-Australia dan bagian timur Indonesia yang dipengaruhi oleh lempeng Pasifik.

Pengembangan wilayah berbasis struktur geologi kawasan merupakan kajian dari pengembangan suatu wilayah dengan mengkaji struktur geologi yang terdapat pada kawasan tertentu. Struktur geologi pada setiap wilayah sangatlah berbeda antara satu sama lain sehingga data mengenai struktur geologi sangat diperlukan untuk mendukung pengembangan wilayah berbasis struktur geologi kawasan. Pengkajian struktur geologi kawasan ini berguna untuk menginformasikan mengenai berbagai potensi, masalah seta ancaman geologi yang akan timbul dalam pengembangan suatu kawasan, khususnya untuk pengembangan wilayah Pulau Belitung yang mulai tumbuh seiring dengan beralihnya kegiatan pertambangan ke kegiatan pariwisata sebagai prioritas pengembangan wilayah, khususnya di Kabupaten Belitung dan Kabupaten Belitung Timur.

Khusus untuk Pulau Belitung, struktur geologi wilayahnya tersusun dari sembilan jenis formasi geologi batuan yang terdiri dari Formasi Kelapakampit (PCKs), Formasi Granit Tanjungpandan (Trtg), 
Formasi Tajam (PCTm), Formasi Adamelit Baginda (Jma), Formasi Granodiorit Burungmandi (Kbg), Formasi Pasir Karbonan (Qpk), Formasi Siantu (PCk), Formasi Diorit Kuarsa Batubesi (Kbd) dan Endapan Aluvial dan Pantai (Qa). (Aditya F. Putrananda, Mega F. Rosana, Kurnia A Fachrudin, 2019). Sedangkan untuk bentuk fisik batuannya terbagi menjadi tiga jenis, yaitu batuan beku (Formasi Tanjungpandan, Formasi Baginda, Formasi Siantu dan Formasi Burungmandi), batuan sedimen (Formasi Pasir Karbonan, Batubesi, Alluvial Dan Pantai dan Formasi Tajam) serta batuan malihan (Formasi Kelapakampit). Untuk batuan beku pada formasi geologi Pulau Belitung memiliki usia sekitar 115-250 juta tahun, kemudian untuk batuan sedimen dan malihan berusia sekitar 1,6 -290 juta tahun yang lalu.

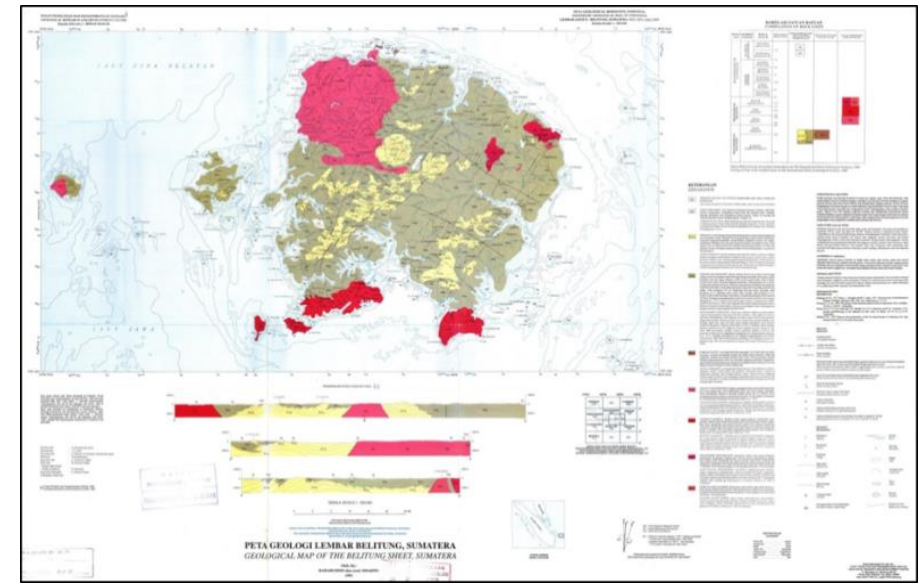

Gambar 1.1 Struktur Geologi Pulau Belitung

Sumber : www.indonesia geospasial.com, 2021

Sebagai kawasan yang baru dikembangkan menjadi kawasan pariwisata, Pulau Belitung harus mempunyai rujukan untuk pengembangan wilayah kedepannya seiring dengan peningkatan aktivitas pariwisata pulau dan untuk mengurangi resiko bencana yang diakibatkan dari pemanfaatan manusia terhadap struktur geologi setempat. Pengembangan Wilayah berbasis Struktur Geologi Kawasan dapat menjadi acuan dalam pengembangan setiap wilayah yang tidak ditujukan pada kawasan pariwisata saja, namun juga dapat dikembangkan kearah selain dari pariwisata agar pemanfaatan wilayah tidak terlalu monoton untuk kegiatan pariwisata saja.

\section{DATA DAN METODE}

Metode yang digunakan dalam penyusunan artikel ini adalah metode kajian literatur (literature review). Kajian literatur ini membahas mengenai topik suatu kajian serta mengevaluasi dari temuan-temuan penelitian atau pengamatan langsung. Dalam mencari sumber literatur ini menggunakan media dari buku dan juga jurnal online sebagai prosedur pemecahan masalah yang diselidiki dengan menggambarkan keadaan subjek atau objek dalam penyusunan artikel bersumber dari jurnal, berita, dan buku berserta fakta yang ada serta kondisi yang berkaitan dengan pembahasan pengembangan wilayah berbasis struktur geologi kawasan.

\section{HASIL DAN PEMBAHASAN}

Setiap wilayah memiliki struktur dan pola ruangnya masing-masing. Struktur wilayah memiliki definisi berupa susunan dari sistem pemukiman-pemukiman dan sistem jaringan daerah yaitu sarana-prasarana daerah yang memiliki fungsi sebagai pendukung kegiatan sosial-ekonomi masyarakat yang mempunyai keterkaitan secara fungsional. Sedangkan pola ruang yaitu persebaran distribusi ruang pada suatu wilayah yang berkaitan dengan peruntukuan ruang seperti fungsi lindung dan budidaya. (Basuki, 2019)

Kebutuhan data struktur geologi pada suatu wilayah sangatlah penting dalam pengembangan wilayah karena hasil kajian ini nantinya bisa mengklasterkan beberapa kawasan yang memiliki potensi serta ancaman bahaya geologi yang senantiasa mengintai suatu kawasan, sehingga kajian ini sangat penting 
dalam mengurangi resiko bencana yang timbul dari pengembangan suatu kawasan, baik untuk kawasan lindung maupun kawasan budidaya.



Gambar 1.2 Peta RTRW Kabupaten Belitung Sumber : https://bappeda.belitungkab.go.id

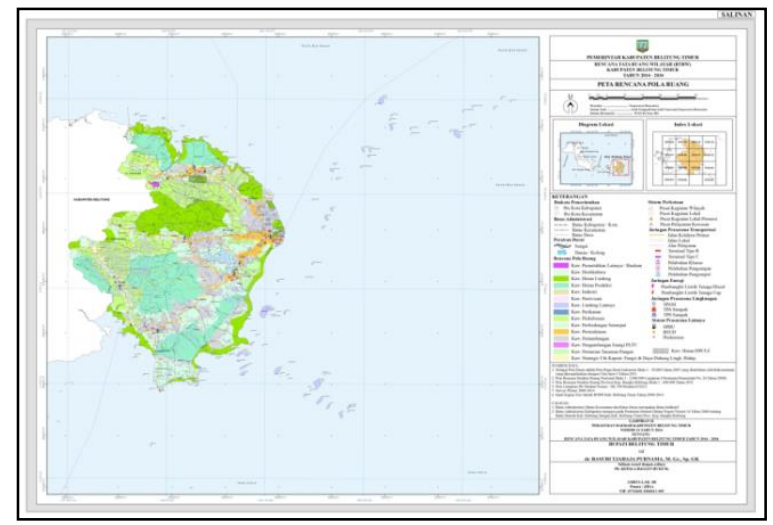

Gambar 1.3 Peta RTRW Kabupaten Belitung Sumber : https://jdih.belitungtimurkab.go.id

Pulau Belitung termasuk pada wilayah administrasi Provinsi Kepulauan Bangka Belitung yang memiliki luas wilayah sebesar $4.800 \mathrm{~km} 2$ yang terbagi menjadi dua kabupaten. Kabupaten yang membawahi Pulau Belitung yaitu Kabupaten Belitung dengan luas wilayah sebesar 2.293,69 km2 dan Kabupaten Belitung Timur dengan luas wilayah sebesar 2.506,91 km2. Berdasarkan struktur geologinya, Pulau Belitung terbagi menjadi sembilan formasi batuan, dengan formasi terbesar adalah Formasi Kelapa Kampit dan formasi batuan terkecil yaitu Formasi Diorit Kuarsa Batubesi. Pengembangan wilayah pada kawasan Pulau Belitung kebanyakan hanya berada pada kawasan perkotaan kawasan wisata. Kawasan wisata yang berkembang juga berada pada kawasan pesisir yang sebagian besar kawasan pesisir tersusun dari jenis formasi aluvium yang sangat rentan akan bahaya land subsidence jika pengembangan wilayah terjadi secara massive dan tidak terkontrol. Wilayah lainnya yang berkembang sebagian besar terfokus pada kawasan yang sebelumnya telah memiliki kegiatan-kegiatan tertentu dan kebanyakan kegiatan-kegiatan tersebut berupa kawasan perkebunan kelapa sawit dan pertambangan timah. Padahal, jika pengembangan wilayah juga mengkaji struktur geologi setempat maka banyak yang bisa dipergunakan dan pada struktur geologi kawasan tersebut.

\section{A. Kondisi Struktur Geologi Pulau Belitung}

Menurut struktur geologi penyusun Pulau Belitung, terdapat sembilan formasi geologi yang klasifikasi jenis geologinya dibedakan dari kondisi fisik batuan, letak keberadaan formasi geologinya serta usia pembentukan dari formasi-formasi batuannya.

a) Formasi Aluvial dan Pantai (Qa) 
Formasi alluvial dan pantai merupakan formasi geologi dengan umur termuda diantara semua formasi batuan penyusun Pulau Belitung. Formasi ini berusia 0,01 juta tahun atau terbentuk pada masa Holosen. Formasi ini terdiri dari endapan kerikil-kerakal, endapan sedimentas sungai (pasir, lanau, dan lempung) atau terbentuk dari pecahan karang dan koral. Persebaran formasi ini berada pada sebagian besar wilayah pesisir pulau.

\section{b) Formasi Pasir Karbonan (Qpk)}

Formasi pasir karbonan merupakan formasi geologi penyusun pulau yang terdiri dari mineral lignit dan mineral kasisterit. Formasi pasir karbonan terbentuk dari masa pleistosen dengan umur 1,6 juta tahun. Formasi ini memiliki ketebalan lapisan sebesar 1 hingga 5 meter.

\section{c) Formasi Tajam (PCTm)}

Formasi Tajam terdiri dari batuan sedimen berjenis batupasir kuarsa dan batulanau dengan ciri fisik berwarna putih-hijau, padat, butiran halus-kasar, lapisan sejajar dan bersusun. Lapisan ini memiliki ketebalan 2 hingga $40 \mathrm{~cm}$. Pada lapisan ini dapat ditemukan urat biji timah yang terdapat pada lapisan batupasir kuarsa dengan urat rekah dan berjejaring. Usia formasi ini mencapai 290 hingga 300 juta tahun dengan pembentukan formasi pada masa perm-karbon. Lapisan ini menjemari dengan Formasi Kelapakampit.

d) Formasi Kelapakampit (PCks)

Formasi Kelapakampit merupakan formasi penyusun terbesar dari Struktur Geologi Pulau Belitung. Formasi ini tersusun dari batuan sedimen berupa batupasir, batusabak, batulumpur, batulanau tuf, batuan serpih dan rijang. Tebal perlapisan 2-6 meter, pada formasi setempat dijumpai struktur sedimen berupa lapisan bersusun (graded bedding), silang-siur (cross bedding) dan gelembur bergelombang (ripple mark). Lapisan ini memiliki ketebalan 1 hingga 6 meter.

Pada formasi ini juga terdapat fosil biota laut seperti Aghaticerassundaicum, Moscovicrinus, Fusulinaschwargerina dan Cathaysia (Gigantophis). Dari kumpulan fosil ini menunjukkan bahwa formasi ini berumur Perm-Karbon dengan usia 290 hingga 300 juta tahun. Formasi ini terendapkan pada lingkungan laut dengan ketebalan lebih dari 500 meter.

e) Formasi Siantu (PCsv)

Formasi Siantu terbentuk dari lava basal dan breksi dari gunungapi. Ciri fisik batuan yang terdapat pada formasi ini yaitu berbentuk basalt, berwarna hijau tua-merah, tersusun dari mineral plagioklas, piroksin dan mineral sekunder klorit. Formasi ini hanya berada pada kawasan Pantai Tanjung Siantu, Kecamatan Sijuk yang disebut kawasan lava bantal dan ada yang berada pada bawah laut. Keberadaan formasi ini menjemari dengan Formasi Kelapakampit.

f) Formasi Granit Tanjungpandan (Trtg)

Formasi Granit Tanjungpandan merupakan formasi batuan beku terbesar di Pulau Belitung dengan dengan ciri fisik berbentuk granit berwarna abu-abu hingga kehijauan, butir kasar dengan mineral penyusun yaitu kuarsit, feldspar, plagioklas, biotit, klorit, karbonat, limonit dan oksida besi. Formasi ini beusia 208 hingga 245 juta tahun atau terbentuk pada masa Trias.

\section{g) Formasi Adamelit Baginda (Jma)}

Formasi Adamelit Baginda tersusun dari batuan granit yang berusia 160 hingga 208 juta tahun dengan ciri fisik yang hampir sama dengan batuan granit Formasi Tanjungpandan. Namun pembedanya adalah sifat formasi ini adalah hipidiomorfik yaitu kristal penyusun batuan bersifat menengah. Persebaran formasi batuan ini terdapat pada bagian selatan Pulau Belitung, Tepatnya berada pada Kecamatan Membalong dan Kecamatan Simpangpesak.

h) Formasi Granodiorit Burungmandi (Kbg) 
Formasi Burungmandi tersusun dari batuan granit dengan mineral penyusunnya yaitu kuarsa, plagioklas, feldspar dan horenblenda. Secara fisik, batuan granit Burungmandi berwarna kelabu muda hingga kehijauan, hipidiomorfik, ekigranular dan holokristalin. Batuan granit formasi ini terbentuk dari masa kapur yang berusia 115-160 juta tahun. Formasi batuan ini hanya terdapat pada sekitar Desa Burungmandi, Kecamatan Damar.

i) Diorit Kuarsa Batubesi (Kbd)

Diorit Kuarsa Batubesi merupakan jenis batuan beku yang tersusun dari mineral kuarsa, plagioklas, K-Feldspar, biotit, horenblenda, klorit dan oksida besi. Formasi batuan ini terbentuk dari masa kapur dengan usia 115-160 Juta tahun. Persebaran formasi ini hanya terdapat pada Gunung Batubesi, Kecamatan Damar.

\section{B. Arahan Pengembangan Wilayah}

Suatu wilayah dikatakan berkembang apabila pada suatu wilayah terdapat pertumbuhan, baik pertambahan penduduk, pertambahan kawasan yang terbangun, dan pertambahan kawasan yang digunakan untuk kegiatan masyarakat. Selain itu kebutuhan akan ruang yang lebih banyak sebagai dampak dari pola aktivitas masyarakat yang beragam dan heterogen. Di samping dengan kenaikan intensitas aktivitas kehidupan sosial ekonomi masyarakat kota yang terefleksi dalam bentuk penambahan ruang kota tentunya akan meningkat pula (Samli, 2012). Pada saat ini, pengembangan wilayah hanya berfokus pada kawasan-kawasan perkotaan atau kawasan industri saja, sedangkan pada kawasan lainnya masih belum dikelola secara optimal padahal apabila selurih kawasan diarahkan untuk menjadi wilayah yang berkembang maka seluruh masyarakat dan juga pemerintah akan merasakan manfaatnya. Pengembangan wilayah berbasis strutur geologi kawasan juga bisa membantu mengurangi dampak dari bencana alam geologi yang terjadi pada suatu kawasan tertentu. (Darmawan \& Lastiadi, 2010).

- Pengembangan Kawasan Berstruktur Geologi Batuan Beku (Formasi Tanjungpandan, Formasi Adamelit Baginda, Formasi Burungmandi dan Formasi Siantu)

Untuk kondisi struktur geologi Pulau Belitung yang terdiri dari sembilan formasi yaitu Formasi Kelapakampit (PCKs), Formasi Granit Tanjungpandan (Trtg), Formasi Tajam (PCTm), Formasi Adamelit Baginda (Jma), Formasi Granodiorit Burungmandi (Kbg), Formasi Pasir Karbonan (Qpk), Formasi Siantu (PCk), Formasi Diorit Kuarsa Batubesi (Kbd) dan Endapan Aluvial dan Pantai (Qa). Perlu diarahkan dalam pengembangan kawasan tersebut. Kawasan-kawasan yang memiliki struktur batuan beku memiliki tingkat kekerasan batuan yang cukup tinggi, untuk tingkat kekerasan batuan granit menurut skala mohs sebesar 7 skala Mohs, kuat tekan $1180-2650 \mathrm{~kg} / \mathrm{cm} 2$, Kepadatan rata-rata Granit adalah 2,75 gr/ $\mathrm{cm}^{3}$ dengan jangkauan antara 1,74 dan 2,80, bersifat kedap air, kaku (rigid), nonhigroskopis dan memiliki koefisien ekspansi termal yang sangat rendah (Juliansyah, Ratnawulan, \& Fauzi, 2015) sehingga apabila dikembangkan menjadi kawasan-kawasan industri, ekonomi dan bisnis atau kawasan pemukiman warga bisa menjadi usulan pengembangan wilayah. Selain itu, khusus untuk kawasan yang berada pada Formasi Tanjungpandan dan Formasi Adamelit Baginda memiliki keunikan, yaitu terdapat gugusan-gugusan batuan granit raksasa yang menjulang tinggi, dan menawarkan panorama alam yang indah sehingga kawasan ini sangat potensial untuk dikembangkan sebagai kawasan pariwisata, tepatnya untuk kawasan geowisata. (Hermawan \& Ghani, 2018).

- Pengembangan Kawasan Berstruktur Geologi Batuan Sedimen-Malihan (Formasi Kelapakampit, Formasi Tajam, Formasi Pasir Karbonan, Formasi Aluvial dan Pantai)

Pengembangan kawasan yang berada pada formasi geologi berjenis batuan sedimen ini dapat dikembangkan menjadi beberapa hal, namun harus memperhatikan kondisi alam setempat. Pada kawasan yang memiliki struktur geologi Formasi Tajam sebagian besar dijumpai pada areaarea perbukitan, dengan jenis vegetasi berupa hutan kerangas yang menyebabkan kawasan perbukitan ini harus menjadi kawasan lindung setempat. Kawasan lindung ini selain untuk melindungi struktur geologi dibawahnya juga melindungi kawasan tangkapan air hujan (catchment 
area) sebagai area resapan air. Karena pada Formasi Tajam sering dijumpai jalur/urat biji timah primer, maka keberadaan biji timah ini harus dijaga dan dilestarikan agar cadangan mineral tambang, khususnya timah masih bisa terus dimanfaatkan hingga ke generasi penerus.

Pada kawasan bersturktur geologi Formasi Kelapakampit, yang tersusun dari batupasir, batulanau, batusabak, batulumpur, batulanau tuf dan batuan serpih lebih cocok untuk dikembangkan menjadi kawasan pertanian dan perkebunan. Kawasan pertanian disini bukan merupakan area pertanian lahan basah (sawah) karena kondisi batuan dan tanahnya yang miskin akan unsur organik. Kawasan ini cocok untuk dikembangkan sebagai area pertanian lahan kering (padi ladang). Pertanian area kering dapat dikembangkan pada kawasan yang memiliki struktur batuan dan yang kurang subur serta ketersediaan air yang sangat minim.(Matheus, Basri, Rompon, \& Neonufa, 2017). Area formasi kelapakampit bisa dikembangkan sebagai area pertanian lahan kering sebagai solusi alternatif masyarakat Pulau Belitung dalam upaya swasembada pangan serta untuk mengurangi ketergantungan pasokan beras dari luar pulau. Untuk perkebunan bisa dikembangkan menjadi kawasan perkebunan kelapa sawit, kelapa, lada, cengkeh dan buah-buahan seperti durian, dan langsat. Untuk kawasan pertambangan timah mayoritas berada pada struktur geologi ini karena mineral timah sekunder banyak dijumpai pada kawasan endapan sungai-sungai purba.

Sedangkan pada kawasan Pasir Karbonan yang berasal dari material endapan hasil pelapukan mineral kimia sehingga kawasan ini sangat tidak subur dan tidak bisa dimanfaatkan untuk kegiatan tertentu. Pada kawasan berstruktur geologi alluvial dan pantai cocok untuk dikembangkan sebagai kawasan pariwisata atau sebagai kawasan perlindungan pantai, karena bentukalamnya yang berupa pantai berpasir dan pantai dengan hutan mangrove. Pantai dengan hutan mangrove dapat dijadikan sebagai area lindung pantai sebagai upaya alami untuk menangkal bahaya abrasi pantai serta bisa dijadikan sebagai perlindungan jenis biota laut yang terdapat pada kawasan hutan mangrove tersebut.

Tabel Indikator, Variabel, Analisis Pengembangan Wilayah berdasarkan Struktur Geologi

\begin{tabular}{|c|l|l|l|}
\hline \multirow{2}{*}{ Nomor } & \multirow{2}{*}{ Jenis Struktur Geologi } & \multicolumn{1}{|c|}{ Indikator } & \multicolumn{1}{|c|}{ Parameter } \\
\cline { 3 - 4 } & \multirow{2}{*}{$\begin{array}{l}\text { Formasi Endapan } \\
\text { Aluvium dan Pantai }\end{array}$} & $\begin{array}{l}\text { Pengembangan Kawasan } \\
\text { Wisata dan Kawasan Lindung } \\
\text { Pantai }\end{array}$ & $\begin{array}{l}\text { Jenis batuan berupa batupasir, } \\
\text { batulanau, serta pecahan koral. } \\
\text { Terdapat vegetasi mangrove pada } \\
\text { kawasan formasi tersebut }\end{array}$ \\
\hline 3 & Formasi Pasir Karbonan & Tidak ada & $\begin{array}{l}\text { Terbentuk dari hasil endapan } \\
\text { material mineral kimawi hasil } \\
\text { aktivitas magmatis }\end{array}$ \\
\hline 4 & Formasi Tajam & $\begin{array}{l}\text { Pengembangan Kawasan } \\
\text { Lindung }\end{array}$ & $\begin{array}{l}\text { Jenis batuan berupa batupasir } \\
\text { kuarsa, batulanau, terdapat urat biji } \\
\text { timah primer serta berada pada } \\
\text { kawasan perbukitan }\end{array}$ \\
\hline 5 & Formasi Kelapakampit & $\begin{array}{l}\text { Pengembangan Kawasan } \\
\text { Pertanian Lahan Kering dan } \\
\text { Kawasan Perkebunan }\end{array}$ & $\begin{array}{l}\text { Kondisi batuan berupa batupasir, } \\
\text { batulanau, batuserpih, batulumpur } \\
\text { dan batusabak, sebagian besar } \\
\text { kondisi lingkungan kering dan minim } \\
\text { air }\end{array}$ \\
\hline & Formasi Siantu & Pengembangan Kawasan & $\begin{array}{l}\text { Kondisi batuan tersusun dari batu } \\
\text { breksi dan batu basal, terbentuk dari } \\
\text { intrusi lava ke permukaan bumi dan } \\
\text { membentuk lava bantal setelah } \\
\text { kontak dengan air laut }\end{array}$ \\
\hline
\end{tabular}




\begin{tabular}{|c|l|l|l|}
\hline 6 & $\begin{array}{l}\text { Formasi Granit } \\
\text { Tanjungpandan }\end{array}$ & $\begin{array}{l}\text { Pengembangan Kawasan } \\
\text { Wisata, Kawasan Ekonomi dan } \\
\text { Bisnis dan Kawasan } \\
\text { Pemukiman }\end{array}$ & $\begin{array}{l}\text { Tersusun dari batuan granit berumur } \\
\text { trias dengan tingkat kekerasan } 7 \\
\text { skala mohs, terdapat kawasan } \\
\text { perkotaan dan gugusan batuan } \\
\text { raksasa }\end{array}$ \\
\hline 7 & $\begin{array}{l}\text { Formasi Adamelit } \\
\text { Baginda }\end{array}$ & $\begin{array}{l}\text { Pengembangan Kawasan } \\
\text { Wisata }\end{array}$ & $\begin{array}{l}\text { Tersusun dari batuan granit berumur } \\
\text { jura dengan tingkat kekerasan 7 skala } \\
\text { mohs, terdapat gugusan batuan } \\
\text { raksasa }\end{array}$ \\
\hline 8 & $\begin{array}{l}\text { Formasi Granodiorit } \\
\text { Burungmandi }\end{array}$ & $\begin{array}{l}\text { Pengembangan Kawasan } \\
\text { Wisata }\end{array}$ & $\begin{array}{l}\text { Tersusun dari batuan granit berumur } \\
\text { kapur dengan tingkat kekerasan } 7 \\
\text { skala mohs, terdapat gugusan batuan } \\
\text { raksasa }\end{array}$ \\
\hline 9 & $\begin{array}{l}\text { Formasi Diorit Kuarsa } \\
\text { Batubesi }\end{array}$ & $\begin{array}{l}\text { Pengembangan Kawasan } \\
\text { Pertambangan }\end{array}$ & $\begin{array}{l}\text { Terdapat batuan kuarsa dengan } \\
\text { berbagai macam warna yang cocok } \\
\text { sebagai batu akik }\end{array}$ \\
\hline
\end{tabular}

Sumber : Hasil Analisis Bersama,2021

\section{KESIMPULAN}

Struktur Geologi Pulau Belitung terdiri dari 9 jenis formasi batuan, diantaranya yaitu Formasi Kelapakampit (PCKs), Formasi Granit Tanjungpandan (Trtg), Formasi Tajam (PCTm), Formasi Adamelit Baginda (Jma), Formasi Granodiorit Burungmandi (Kbg), Formasi Pasir Karbonan (Qpk), Formasi Siantu (PCk), Formasi Diorit Kuarsa Batubesi (Kbd) dan Endapan Aluvial dan Pantai (Qa). Dari 9 formasi batuan dikelompokkan menurut jenis batuan, yaitu batuan beku (Formasi Tanjungpandan, Formasi Adamelit Baginda, Formasi Granodiorit Burungmandi, Formasi Diorit Kuarsa Batubesi dan Formasi Siantu), batuan sedimen (Formasi Endapan Aluvial dan Pantai, Formasi Pasir Berkarbon, Formasi Tajam) dan batuan malihan (Formasi Kelapakampit). Dari ketiga jenis batuan dan struktur geologinya, masing-masing struktur geologi cocok untuk dikembangkan menjadi berbagai arah, untuk kawasan berstruktur batuan beku dikembangkan sebagai kawasan wisata, pertambangan, kawasan pemukiman dan kawasan ekonomi dan bisnis. Sedangkan untuk kawasan berstruktur batuan sedimen dikembangkan sebagai kawasan lindung dan kawasan batuan malihan dikembangkan sebagai pertanian lahan kering dan perkebunan.

Dalam melakukan kajian mengenai pengembangan wilayah berbasis struktur geologi kawasan akan lebih maksimal jika menggunakan metode kajian literatur dan metode observasi langsung dengan cara pengamatan langsung sehingga objek penlitian termasuk fokus masalah yang diteliti bisa dibahas secara rinci dan sesuai dengan kondisi lapangan.

\section{UCAPAN TERIMA KASIH}

Pertama tim penulis mengucap syukur kepada Tuhan yang maha esa karena telah diberikan kesehatan serta rezeki yang cukup sehingga tim tidak mengalami kendala dalam penulisan dan penelitian jurnal ini. Rasa terimakasih kami ucapkan kepada Universitas Islam Sultan Agung, program studi Perencanaan Wilayah dan Kota yang telah mewadahi pembelajaran dalam pemberian materi untuk penulisan jurnal ini. Kemudian juga kepada dosen pembimbing yaitu Bapak Boby Rahman, ST., MT. dan juga Bu Hasti Widyasamratri, S.Si., M.Eng., Ph.D serta tim penulis yang telah membantu dalam penulisan jurnal ini. Terakhir kami mengucapkan terimakasih kepada pihak lain yang juga ikut mensupport kami.

\section{DAFTAR PUSTAKA}

Aditya F. Putrananda, Mega F. Rosana, Kurnia A Fachrudin, A. S. (2019). Fakultas Teknik Geologi Universitas Padjadjaran. 3(5), 312-323.

Basuki, K. (2019). Rencana Tata Ruang Wilayah Sebagai Arahan Spasial RPI2-JM. ISSN 2502-3632 (Online) ISSN 2356-0304 (Paper) Jurnal Online Internasional \& Nasional Vol. 7 No.1, Januari - Juni 2019 
Universitas 17 Agustus 1945 Jakarta, 53(9), 1689-1699. Retrieved from www.journal.uta45jakarta.ac.id

Darmawan, A., \& Lastiadi, H. A. (2010). Geologi lingkungan dan fenomena kars sebagai arahan pengembangan wilayah perkotaan Kupang, Nusa Tenggara Timur. Jurnal Lingkungan Dan Bencana Geologi, 1(1), 11-26. Retrieved from http://jlbg.geologi.esdm.go.id/index.php/jlbg/article/view/2

Hermawan, H., \& Ghani, Y. A. (2018). Geowisata: Solusi Pemanfaatan Kekayaan Geologi yang Berwawasan Lingkungan. Jurnal Ekowisata Dan Geografi Pariwisata. https://doi.org/10.31227/osf.io/a5xd6

Juliansyah, Ratnawulan, \& Fauzi, A. (2015). Pengaruh Temperatur Kalsinasi Terhadap Struktur Mineral Granit yang Terdapat di Nagari Surian Kecamatan Pantai Cermin Kabupaten Solok. Pillar of Physics, 9, 9-16.

Matheus, R., Basri, M., Rompon, M. S., \& Neonufa, N. (2017). Strategi Pengelolaan Pertanian Lahan Kering Dalam Meningkatkan Ketahanan Pangan Di Nusa Tenggrara Timur. Partner, 22(2), 529. https://doi.org/10.35726/jp.v22i2.246

Samli, A. (2012). Analisis Pengembangan Kota Berdasarkan Kondisi Fisik Wilayah Kota Masohi Ibukota Kabupaten Maluku Tengah. Jurnal Plano Madani, I(1), 74-85.

Sumber Buku :

Baharudin \& Sidharto, 1995. Peta Geologi Lembar Belitung, Sumatra, Skala 1 : 250.000, Bandung : Pusat Penelitian Pengembangan Geologi,

Humas Pemkab Belitung. (2013). Potret Belitung. Tanjungpandan: PT. Adhi Cipta Arthapura

Husin Abdullah, Husnial. (1981). Sejarah Perjuangan Kemerdekaan RI di Bangka Belitung. Jakarta: PT. Karya Unipress

Sumber Gambar :

https://bappeda.belitungkab.go.id/Peta RTRW Kabupaten Belitung

www.indonesia geospasial.com/Peta Geologi Lembar Belitung, Sumatera

https://jdih.belitungtimurkab.go.id/Peta RTRW Kabupaten Belitung Timur 